\title{
Role of grain size on the stress corrosion cracking of 7475 aluminum alloys
}

\author{
T.C. Tsai, T.H. Chuang * \\ Institute of Materials Science and Engineering, National Taiwan University, Taipei, Taiwan, ROC
}

Received 22 August 1996

\begin{abstract}
The effect of grain size upon the stress corrosion cracking of 7475 Al-alloy plates has been investigated. Grain refinement resulted in a more homogeneous slip mode and a smaller size of grain boundary precipitates (GBPs) to influence the stress corrosion cracking (SCC) resistance. The more homogeneous slip mode is always beneficial for improving the SCC resistance. However, if the GBPs size was smaller than a critical precipitate size for nucleating hydrogen bubbles, the improvement of SCC resistance due to grain refinement, resulting from a more homogeneous slip mode, could not be obtained. The correlation of SCC susceptibility and hydrogen embrittlement susceptibility has been evaluated. The SCC susceptibility of the 7475 aluminum alloys is mainly controlled by hydrogen induced cracking mechanism. (C) 1997 Elsevier Science S.A.
\end{abstract}

Keywords: Grain refinement; Grain boundary precipitates; Stress corrosion cracking; Hydrogen embrittlement

\section{Introduction}

High strength $\mathrm{Al}-\mathrm{Zn}-\mathrm{Mg}-\mathrm{Cu}$ (7xxx series) aluminum alloys are widely used in airframe construction. However, this series of alloys are susceptible to stress corrosion cracking (SCC) to limit their usefulness, particularly when they are aged to the near peak strength of T6 temper $[1,2]$. Their susceptibility to SCC can be eliminated by overaging to a $\mathrm{T} 7$ type temper but with a concomitant loss of about $10-15 \%$ in strength. A heat treatment known as retrogression and reaging (RRA) has been developed to give SCC resistance equivalent to that of T73 temper together with T6 strength levels $[3,4]$. This treatment has been applied to material in the T6 condition and consists of reheating the material for a short time in the temperature range of $200-260^{\circ} \mathrm{C}$ (retrogression treatment), followed by reaging using the same conditions as in the original T6 aging process. An optimum condition for the SCC testing is to retrogress the materials at $220^{\circ} \mathrm{C}$ for $5 \mathrm{~min}$, followed by reaging. It has produced the best SCC results $[5,6]$.

Burleigh [2] summarized three main mechanisms for $\mathrm{SCC}$ in aluminum alloys. They are anodic dissolution,

\footnotetext{
* Corresponding author. Tel.: + 886023630231 ; fax: +88602 3934562.
}

hydrogen induced cracking (HIC) and passive film rupture. He also indicated that anodic dissolution is generally favored in the $2 \mathrm{xxx}$ series aluminum alloys while HIC is favored in the $7 \times x x$ series. It is well known that the hydrogen embrittlement ( $\mathrm{HE}$ ) is the most severe for underaged tempers, intermediate for peak strength tempers and minimal for overaged tempers $[7,8]$. The RRA tempered condition could effectively improve the SCC resistance of $7 \mathrm{xxx}$ series alloys in the $\mathrm{T} 6$ temper. It is suggested that the RRA tempered condition can provide a larger size of grain boundary precipitates (GBPs) to nucleate the hydrogen bubble, then reduce the hydrogen concentration in the grain boundary and improve the $\mathrm{HE}$ resistance $[4,6]$.

Grain refinement can be made by thermo-mechanical treatment for $7 \mathrm{xxx}$ series aluminum alloys, and frequently results in beneficial effects for mechanical properties [9-11]. Wanhill and Gestel [9] have even summarized the results of grain refinement on stress corrosion tests. They found that thermo-mechanical treatment is always advantageous to the SCC resistance, but sometimes grain refinement has no profit on improving the SCC resistance. Fine grain microstructure in high strength aluminum alloys, such as 7475 aluminum alloy, has been commercialized and applied in air frame constructions by using a superplastic form- 
Table 1

Chemical Compositions (wt.\%) of the 7475 aluminum alloys

\begin{tabular}{llllllllll}
\hline Alloy & $\mathrm{Zn}$ & $\mathrm{Mg}$ & $\mathrm{Cu}$ & $\mathrm{Cr}$ & $\mathrm{Fe}$ & $\mathrm{Si}$ & $\mathrm{Mn}$ & $\mathrm{Ti}$ & $\mathrm{Al}$ \\
\hline $7475 \mathrm{~S}$ & 5.80 & 2.24 & 1.53 & 0.19 & 0.08 & 0.02 & 0.01 & 0.02 & Bal. \\
$7475 \mathrm{~L}$ & 5.96 & 2.18 & 1.54 & 0.21 & 0.09 & 0.02 & 0.01 & 0.01 & Bal. \\
\hline
\end{tabular}

Table 2

Intercept grain sizes of the 7475 aluminum alloys

\begin{tabular}{lllc}
\hline Alloy & Longitudinal direction $(\mu \mathrm{m})$ & Long transyerse direction $(\mu \mathrm{m})$ & Short transverse direction $(\mu \mathrm{m})$ \\
\hline $7475 \mathrm{~S}$ & 12.5 & 12.1 & 9.2 \\
$7475 \mathrm{~L}$ & 110.8 & 93.6 & 16.6 \\
\hline
\end{tabular}

ing process $[12,13]$. Shin et al. [14] found that a maximum ductility of approximately $2000 \%$ could be obtained when the tensile specimens of the fine-grained 7475 alloy were tested at $530^{\circ} \mathrm{C}$ and at an initial strain rate of $2.8 \times 10^{-3} \mathrm{~s}^{-1}$. However, a superplastic 7475 alloy was found to suffer from atmospheric SCC if it was treated in $\mathrm{T} 4$ and $\mathrm{T} 6$ tempered conditions [15]. It indicated that a superplastically formed workpiece of superplastic 7475 aluminum alloy is necessary to pay attention to the property of SCC susceptibility. Therefore, a detailed understanding of the effect of grain size on SCC resistance needs to be achieved.

The microstructural characteristics of $7 \mathrm{xxx}$ series aluminum alloys are well known to have a strong effect on SCC susceptibility. The major microstructural features have been discussed concerning the influence of SCC to be the precipitate free zone (PFZ), the matrix precipitate structure and the GBP structure [16-18]. The purpose of this investigation is to evaluate the relationship between SCC susceptibility and HE susceptibility, and use the hydrogen induced cracking mechanism to analyze the influence of grain size upon the SCC susceptibility.

\section{Experimental procedures}

\subsection{Materials and heat treatments}

The material used in this study was a commercial superplastic 7475 aluminum alloy $(7475 \mathrm{~S})$ in T4 tempered condition. The nominal chemical composition is listed in Table 1. This material, supplied as a $2 \mathrm{~mm}$ thick plate, possessed an average grain size of about 10 $\mu \mathrm{m}$ as shown in Table 2 . All the heat treatment procedures including the T4, T6, RRA and T73 conditions are described in Table 3.

A commercial, non-superplastic and $2 \mathrm{~mm}$ thickness 7475 (7475L) aluminum alloy plate with average grain size of about $100 \mu \mathrm{m}$ was also used in this investigation.
The chemical composition of $7475 \mathrm{~L}$ alloy is also shown in Table 1. The SCC resistance of this $7475 \mathrm{~L}$ alloy was used to compare with that of the fine grained $7475 \mathrm{~S}$ alloy in the T6 and T73 tempered conditions. It is helpful for analyzing clearly the influences of grain size and microstructure upon the SCC susceptibility.

\subsection{Mechanical and stress corrosion testing}

Tensile specimens with longitudinal direction for each heat treatment condition were used to measure mechanical properties and aqueous SCC resistances. Rectangular tensile specimens with a gauge length of 25 $\mathrm{mm}$ and a width of $6 \mathrm{~mm}$ were used. Tensile tests were performed at a strain rate of $10^{-3} \mathrm{~s}^{-1}$ in air to obtain $0.2 \%$ offset yield strength, tensile strength and elongation. The SCC tests were assessed by using slow strain rate tests (SSRT) [19]. The SSRT have the advantage that they will promote SCC in systems that in static tests either do not crack or take a particularly long time to show evidence of failure. The specimens of SSRT were tested at a strain rate of $4 \times 10^{-6} \mathrm{~s}^{-1}$ in air and in $3.5 \% \mathrm{NaCl}+0.3 \% \mathrm{H}_{2} \mathrm{O}_{2}$ solution, respectively. The SCC susceptibility for each heat treatment could be evaluated by means of comparing the elongation loss between the elongation of testing in air and testing in stress corrosion solution.

Table 3

Heat treatment procedures for alloy investigated

\begin{tabular}{lll}
\hline Temper & Condition & Aging treatment \\
\hline $\mathrm{T}^{\mathrm{b}}$ & Underaged & As naturally aged to stable \\
$\mathrm{T}^{\mathrm{a}}$ & Near peakaged & $24 \mathrm{~h} / 120^{\circ} \mathrm{C}$ \\
$\mathrm{RRA}^{\mathrm{a}}$ & Peakaged & $\mathrm{T} 6 \mathrm{aged}+5 \mathrm{~min} / 220^{\circ} \mathrm{C}+\mathrm{WQ}+\mathrm{T} 6$ \\
$\mathrm{~T}^{\mathrm{a}} \mathrm{a}$ & Overaged & $6 \mathrm{~h} / 107^{\circ} \mathrm{C}+24 \mathrm{~h} / 163^{\circ} \mathrm{C}$ \\
\hline
\end{tabular}

a Solution treated at $515^{\circ} \mathrm{C}$ for $1.5 \mathrm{~h}+$ water quenched (WQ).

${ }^{b}$ As received for superplastic 7475 aluminum alloy. 


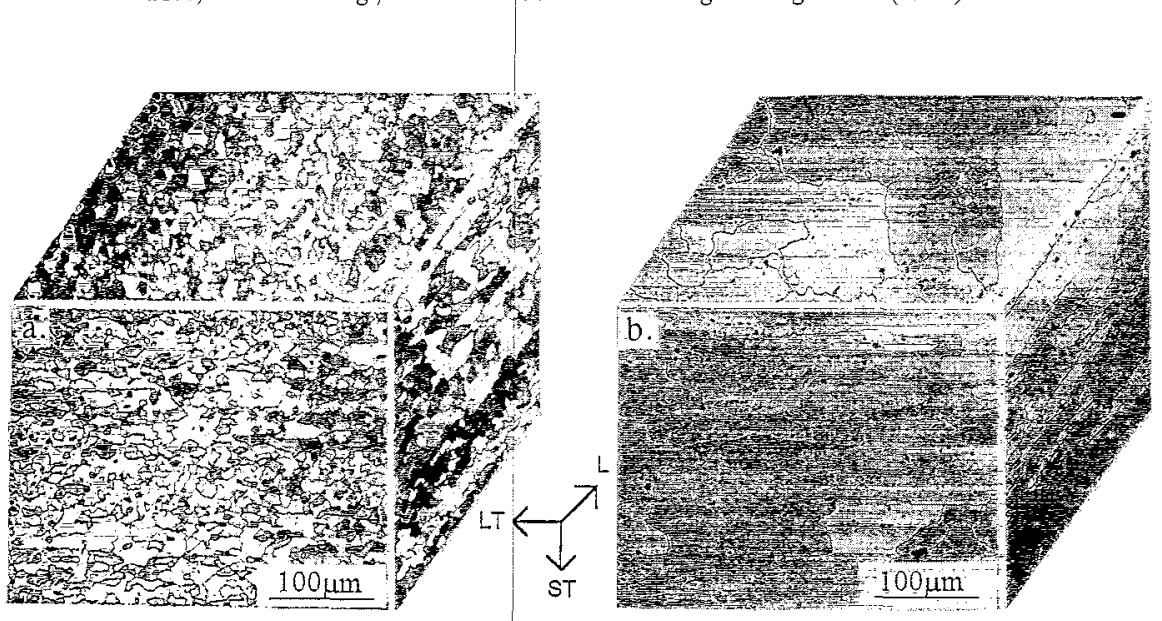

Fig. 1. Three dimensional micrographs showing grain structures of the as-received (a) $7475 \mathrm{~S}$ and (b) $7475 \mathrm{~L}$ aluminum alloy plates.

Table 4

Mechanical properties of tensile test for various tempered conditions ${ }^{2}$

\begin{tabular}{|c|c|c|c|}
\hline Temper & Ultimate strength (MPa) & Yield strength (MPa) & Elongation $(\%)$ \\
\hline $7475 \mathrm{~S}-\mathrm{T} 4$ & 569.1 & 461.5 & 20.0 \\
\hline $7475 \mathrm{~S}-\mathrm{T} 6$ & 592.9 & 511.0 & 16.1 \\
\hline 7475L-T6 & 551.8 & 448.5 & 15.5 \\
\hline 7475S-RRA & 572.3 & 514.5 & 9.6 \\
\hline 7475S-T73 & 500.4 & 356.6 & 13.1 \\
\hline 7475L-T73 & 481.6 & 348.6 & 10.2 \\
\hline
\end{tabular}

a Tensile test at a strain rate of $\dot{\varepsilon}=10^{-3} \mathrm{~s}^{-1}$ in air.

\subsection{Hydrogen embrittlement testing}

For proving the relationship of SCC and HE for all heat treatment conditions, both hydrogen-charged and uncharged tensile specimens for each tempered condition were used to obtain $\mathrm{HE}$ resistances. Tensile tests were performed in air at an initial strain rate of $3.3 \times$ $10^{-4} \mathrm{~s}^{-1}$. At least three charged specimens for each heat treatment condition were prepared by using straining electrod test (SET) method described previously [7]. In this test, specimens were preloaded to approximately $70 \%$ of the yield strength, exposed to the cathodic charging in an electrolyte of $\mathrm{HCl}, \mathrm{pH} \perp$ under a constant potential of $-1500 \mathrm{mV}$ (measured versus a standard calomel electrode, SCE), and then strained at a slow strain rate of $4 \times 10^{-6} \mathrm{~s}^{-1}$. Straining was continued for varying times chosen to correspond to a total plastic strain of about $2 \%$. Following this straining period, the solution was removed, the specimen rinsed and dried, and then pulled to fracture in air at the higher strain rate of $3.3 \times 10^{-4} \mathrm{~s}^{-1}$. The HE susceptibility for each tempered condition could be evaluated by means of comparing the elongation loss between the elongation of uncharged and charged specimens.

\subsection{Microstructure observation}

Optical microscopy (OM) and transmission electron microscopy (TEM) were utilized to observe the microstructural change. Samples for OM were chemically etched in Keller's Reagent, and thin foils were prepared by twin jet electropolishing in a $\mathrm{HNO}_{3}$ : methanol $=2: 1$ solution cooled to $-25^{\circ} \mathrm{C}$, using a potential of $\sim 12 \mathrm{~V}$. TEM quantitative data for the width of the PFZ, the GBP population and size, and the size of the matrix precipitates were characterized by a JEOL 100CXII TEM operating at $100 \mathrm{KV}$. The PFZ width, the GBP size and the number of GBPs per unit area, were determined by using the methods described previously [20]. Slip behavior was investigated using prestrained tensile specimens which were slowly strained to a plastic strain of $4 \%$. Thin foils were made from these specimens and observed in the TEM. Under the same twobeam conditions, the foils were tilted until the slip bands were visible and normal to an operating $\langle\overline{11} 1\rangle g$ vector $[18,20]$. Fractography of all failed SCC and $\mathrm{HE}$ specimens was conducted with a PHILIPS SEM515 scanning electron microscope (SEM) operating at 20 $\mathrm{KV}$. 


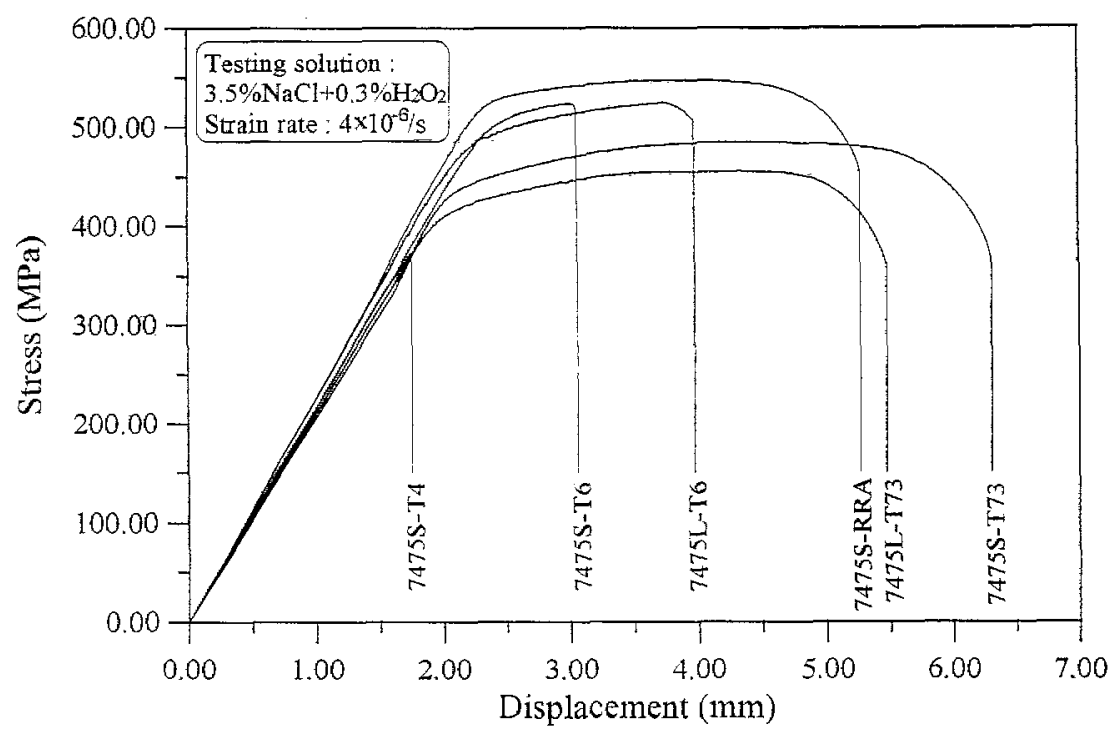

Fig. 2. Stress-displacement curves of the slow strain rate tests for various tempers of the 7475 aluminum alloys.

Table 5

Results of slow strain rate test for various tempered conditions ${ }^{a}$

\begin{tabular}{|c|c|c|c|c|c|c|}
\hline Temper & $E l_{\text {AIR }}^{b}(\%)$ & El. ${ }_{S C C}^{b}(\%)$ & $F E_{\text {AIR }}^{\mathfrak{c}}(\mathrm{J})$ & $F E_{S C C}^{C}(J)$ & $\mathrm{El}_{. \mathrm{scC}} \operatorname{loss}^{\mathrm{b}}(\%)$ & $F E \cdot s c c \mid l o s s^{c}(\%)$ \\
\hline $7475 \mathrm{~S}-\mathrm{T} 4$ & 7.8 & 2.2 & 20.6 & 4.0 & 71.8 & 80.6 \\
\hline $7475 \mathrm{~S}-\mathrm{T} 6$ & 17.6 & 6.7 & 41.5 & 11.7 & 61.9 & 71.8 \\
\hline $7475 \mathrm{~L}-\mathrm{T} 6$ & 16.2 & 8.5 & 39.5 & 15.6 & 47.5 & 60.5 \\
\hline 7475S-RRA & 10.4 & 9.6 & 29.6 & 26.1 & 7.7 & 11.8 \\
\hline $7475 S-T 73$ & 14.2 & 13.7 & 28.9 & 27.2 & 3.5 & 5.9 \\
\hline $7475 \mathrm{~L}-\mathrm{T} 73$ & 11.2 & 10.6 & 25.0 & 23.4 & 5.4 & 6.4 \\
\hline
\end{tabular}

${ }^{2}$ Tensile test at at a strain rate of $\dot{\varepsilon}=4 \times 10^{-6} \mathrm{~s}^{-1}$.

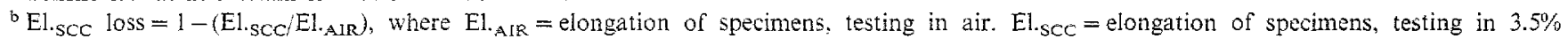
$\mathrm{NaCl}+0.3 \% \mathrm{H}_{2} \mathrm{O}_{2}$ solution.

${ }^{c} \mathrm{FE}_{\mathrm{SCC}}$ loss $=1-\left(\mathrm{FE}_{\mathrm{SCC}} / \mathrm{FE}_{\mathrm{AIR}}\right)$, where $\mathrm{FE}_{\mathrm{AIR}}=$ fracture energy of specimens, testing in air. $\mathrm{FE} \mathrm{Scc}_{\mathrm{SC}}=$ fracture energy of specimens, testing in $3.5 \% \mathrm{NaCl}+0.3 \% \mathrm{H}_{2} \mathrm{O}_{2}$ solution.

\section{Results}

\subsection{Mechanical properties}

Three dimensional optical micrographs of the as-received $7475 \mathrm{~S}$ and $7475 \mathrm{~L}$ alloys are shown in Fig. 1. The difference of grain size between the $7475 \mathrm{~S}$ and $7475 \mathrm{~L}$

Table 6

Results of straining electrode test for various tempered conditions ${ }^{\mathrm{a}}$

\begin{tabular}{|c|c|c|c|}
\hline Temper & $E l_{\text {.uncharged }}(\%)$ & $E 1_{\text {charged }}(\%)$ & $E l_{\mathrm{HE}} \operatorname{loss}^{\circ}(0,0)$ \\
\hline $7475 \mathrm{~S}-\mathrm{T} 4$ & 16.5 & 4.3 & 73,9 \\
\hline $7475 \mathrm{~S}-\mathrm{T} 6$ & 17.1 & 10.2 & 40.4 \\
\hline $7475 \mathrm{~L}-\mathrm{T} 6$ & 16.0 & 12.1 & 24.4 \\
\hline 7475S-RRA & 10.2 & 9.5 & 6.9 \\
\hline $7475 S-T 73$ & 13,9 & 13.5 & 2.9 \\
\hline 7475L-T73 & 10.8 & 10.2 & 5.6 \\
\hline
\end{tabular}

${ }^{a}$ Tensile test at a strain rate of $\dot{\varepsilon}=3.3 \times 10^{-4} \mathrm{~s}^{-i}$ in air.

${ }^{b} \mathrm{El}_{\mathrm{HE}}$ loss $=1-\left(\mathrm{El}_{\text {charged }} / \mathrm{El}_{\text {, uncharged }}\right)$, where $\mathrm{El}_{\text {uncharged }}=$ elongation of uncharged specimens, $E l_{\text {sharged }}=$ elongation of charged specimens. alloys is indicated in Table 2, it shows that the grain shape of the $7475 \mathrm{~L}$ alloy possesses more anisotropy than that of the $7475 \mathrm{~S}$ alloy. Any obvious microstructural difference could not be found for the other heat treatment conditions.

The mechanical properties of the tensile test are shown in Table 4. The yield strength of the 7475S alloy was evidently increased from $T 4$, through $T 6$ to RRA tempered, and decreased from RRA to T73 tempered condition. However, the elongation revealed the opposite relationship of the yield strength. An aging sequence is revealed from $\mathrm{T} 4$, through $\mathrm{T} 6$ and RRA tempered, to T73 tempered condition, and the aging treatment condition for each heat treatment is indicated in Table 3. The yield strength and elongation of the $7475 \mathrm{~S}$ alloy were larger than that of the $7475 \mathrm{~L}$ alloy, as observed from a comparison of the $7475 \mathrm{~S}$ and $7475 \mathrm{~L}$ aluminum alloys in the T6 and T73 tempers. The higher values of mechanical properties for all various tempers of $7475 \mathrm{~S}$ alloy, as demonstrated in Table 4, are a result of grain refinement [9]. 
Table 7

Characteristics of microstructures for various heat treatment conditions ${ }^{\mathrm{a}}$

\begin{tabular}{|c|c|c|c|c|c|c|c|}
\hline \multirow[t]{2}{*}{ Temper } & \multirow[t]{2}{*}{ PFZ width (nm) } & \multicolumn{2}{|l|}{ GBPs } & \multicolumn{2}{|c|}{ Matrix PPTs } & \multicolumn{2}{|l|}{ Slip behavior } \\
\hline & & Size $(\mathrm{nm})$ & No. $\left(\right.$ per $\left.\mu m^{2}\right)$ & Size $(\mathrm{nm})$ & Type & Spacing (nm) & Type \\
\hline $7475 \mathrm{~S}-\mathrm{T} 4$ & 7 & 3.9 & 1400 & 2.6 & GP zones $+\eta^{\prime}+\eta$ & 84 & Planar \\
\hline $7475 S-\mathrm{T} 6$ & 27 & 17.9 & 410 & 5.2 & GP zones $+\eta^{\prime}+\eta$ & 71 & Planar \\
\hline $7475 \mathrm{~L}-\mathrm{T} 6$ & 29 & 25.3 & 320 & 5.0 & GP zones $+\eta^{\prime}+\eta$ & 335 & Planar \\
\hline 7475S-RRA & 35 & 32.8 & 235 & 9.0 & $\eta^{\prime}+\eta$ & 55 & Planar \\
\hline $7475 \mathrm{~S}-\mathrm{T} 73$ & 47 & 48.7 & 135 & 12.4 & $\eta^{\prime}+\eta$ & $<40$ & Wavy \\
\hline $7475 \mathrm{~L}-\mathrm{T} 73$ & 260 & 52.2 & 130 & 14.6 & $\eta^{\prime}+\eta$ & $<60$ & Wavy \\
\hline
\end{tabular}

a Data indicate the average values.

\subsection{Stress corrosion and hydrogen embrittlement susceptibility}

The typical stress-displacement curves of the SCC testing specimens for all heat treatments are indicated in Fig. 2. Generally, if the value of displacement is larger, it means that the SCC resistance of the alloy is better [21]. The fracture energy, which is the area beneath the stress-displacement curve, was also used to evaluate the SCC behavior for each heat treatment [22]. The aqueous $\mathrm{SCC}$ results in a reduction of the fracture energy compared with reference values determined in air. The elongation losses and fracture energy losses for all tempered conditions are given in Table 5. From Fig. 2 and Table 5, the following points should be noted. (1) The values of displacement were in proportion to the values of elongation loss and fracture energy loss for all tempered conditions. These proportional relationships proved that the relative SCC susceptibility for all heat treatments could be directly obtained by comparing the values of displacement of each heat treatment. (2) The SCC resistances for $7475 \mathrm{~S}$ aluminum alloy increased as the aging degree increased. The 7475S-T4 and 7475ST73 tempered condition possessed the largest and the smallest SCC susceptibilities, respectively. The 7475SRRA alloy could effectively improve the aqueous SCC resistance of 7475S-T6 alloy and did not sacrifice mechanical strength. (3) The SCC susceptibility of the $7475 \mathrm{~S}-\mathrm{T} 6$ was larger than that of the $7475 \mathrm{~L}-\mathrm{T} 6$, and conversely, the SCC resistance of $7475 \mathrm{~S}-\mathrm{T} 73$ is better than that of the 7475L-T73.

The results of SET for all heat treatment conditions are shown in Table 6 . The elongation loss following the SET for $7475 \mathrm{~S}$ aluminum alloy was also found to increase with increasing the degree of aging. The HE susceptibility also showed the same tendency as did the SCC susceptibility, as observed from a comparison of the $7475 \mathrm{~S}$ and $7475 \mathrm{~L}$ aluminum alloys in the $\mathrm{T} 6$ and T73.

\subsection{Microstructural characterization}

The data of microstructural characteristics of all heat treatment procedures are summarized in Table 7. Typical PFZ widths, grain boundary $\eta$ precipitates and slip behaviors for the $7475 \mathrm{~S}$ and $7475 \mathrm{~L}$ aluminum alloys under various tempered conditions are shown in Figs. $3-5$, respectively. Only high-angle GBP sizes and distributions were characterized by calculating average precipitate diameters and numbers per unit area $[18,20]$. More than 100 GBPs in five different grain boundary areas were measured for each heat treatment condition to obtain the data of precipitate diameters and numbers per unit area. The sizes and types of matrix precipitates were directly derived from bright field micrographs. The slip behaviors were obtained under the same diffraction conditions and magnifications. The average values of PFZ width, matrix precipitates and GBPs were increased by increasing the aging degree for the $7475 \mathrm{~S}$ aluminum alloy, but it is converse for numbers per unit area and slip band spacings. The 7475S-T4 alloy showed the largest slip band spacing for the $7475 \mathrm{~S}$ aluminum alloy, and the spacing decreased with the increasing degree of aging. This phenomenon is presumably due to the increase of matrix precipitate size, and the associated change from GP zones to semicoherent $\eta$ and incoherent $\eta$ precipitates $[7,18]$.

The comparison of the $7475 \mathrm{~S}$ with $7475 \mathrm{~L}$ aluminum alloys in $\mathrm{T} 6$ tempered condition did not reveal any obvious differences on both the PFZ widths and the sizes of matrix precipitates. Both the 7475S-T73 and $7475 \mathrm{~L}-\mathrm{T} 73$ alloys had also similar sizes of matrix precipitates and GBPs. However, the size of GBPs of $7475 \mathrm{~L}-\mathrm{T} 6$ was larger than that of the 7475S-T6 alloy. The 7475L-T6 and 7475L-T73 alloy possessed wider slip band spacings than the 7475S-T6 and 7475S-T73 alloy, respectively, as indicated by the comparison of Fig. 5(b) with (c) and that of Fig. 5(e) with (f). It means that grain refinement can effectively reduce the coarseness of the slip band and increase the homogeneity of the slip character. The types of matrix slip are also shown in Fig. 5 to transfer from the planar slip type 

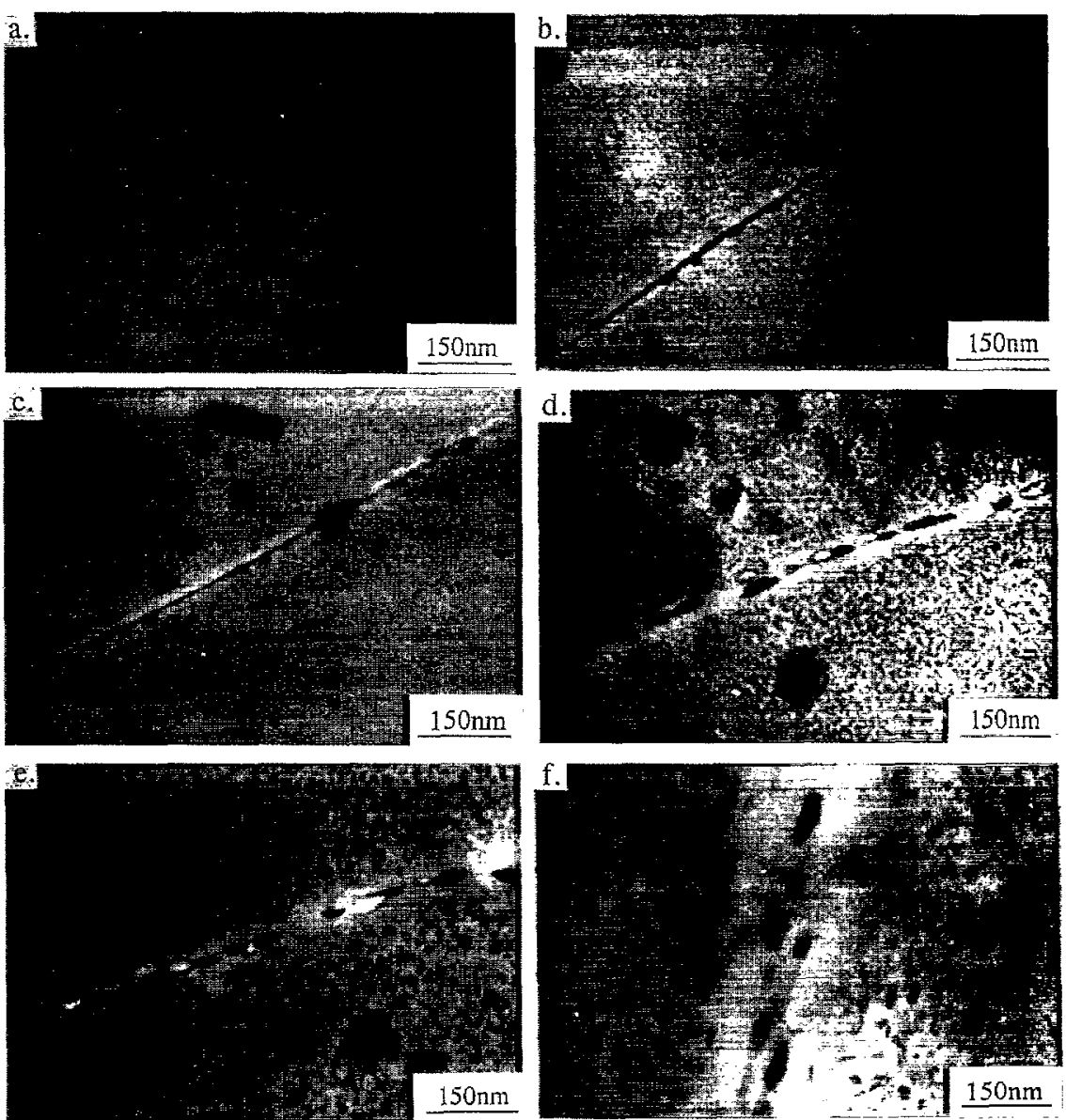

Fig. 3. TEM micrographs showing the precipitate free zone width of the various tempers, (a) 7475S-T4; (b) 7475S-T6; (c) 7475L-T6; (d) 7475S-RRA; (e) 7475S-T73; (f) 7475L-T73.

before overaging (T73) treatment to the wavy slip type after overaging tempered conditions have been reached.

\section{Discussion}

The results of SSRT and SET for all tempered conditions indicate that the hydrogen embrittlement resistances were in proportion to the SCC resistance for all tempered conditions. It directly proves that the HIC plays a main role to control the SCC susceptibility of 7475 aluminum alloys. The fracture surface of a uncharged $7475 \mathrm{~S}-\mathrm{T} 6$ specimen was mainly ductile transgranular nature, as illustrated in Fig. 6(a). The fractographys of a charged 7475S-T6 specimen exhibited some isolated secondary cracks and equiaxed intergranular fracture surfaces, as shown in Fig. 6(b) and (c), respectivity. Fig. 6(d) shows a typical fractography of a charged $7475 \mathrm{~L}-\mathrm{T} 6$ specimen, which appears as a pancake-shaped intergranular fracture surface.

Gruhl [11] indicated that grain refinement can lead to the reduction of planar slip and a more homogeneous slip mode. The homogeneous slip mode can effectively reduce intercrystalline fracture and SCC susceptibility. Therefore, it is reasonable to assume that the SCC resistance of 7475S-T73 alloy is better than 7475L-T73 alloy. The 7475L-T6 alloy is shown from a comparison of Fig. 5(b) with Fig. (c) to possess wider slip band spacings than the 7475S-T6 alloy. Therefore, the SCC susceptibility of 7475L-T6 tempered alloy could be inferred from the above discussions to be larger than that of 7475S-T6 tempered alloy. However, the SCC resistance of 7475L-T6 alloy is shown in Table 5 to be really better than that of 7475 S- 16 alloy. It means that the decrease of the SCC susceptibility which is attributed to the reduction of the slip band spacing by means of grain refinement can not be obtained in 7475S-T6 alloy.

Increasing the matrix precipitate size can generally improve the SCC resistance of high strength aluminum alloys [18], because it can result in the reduction of planar slip and a more homogeneous slip mode. The homogeneous slip mode can effectively reduce hydrogen transported to the grain boundaries to induce 

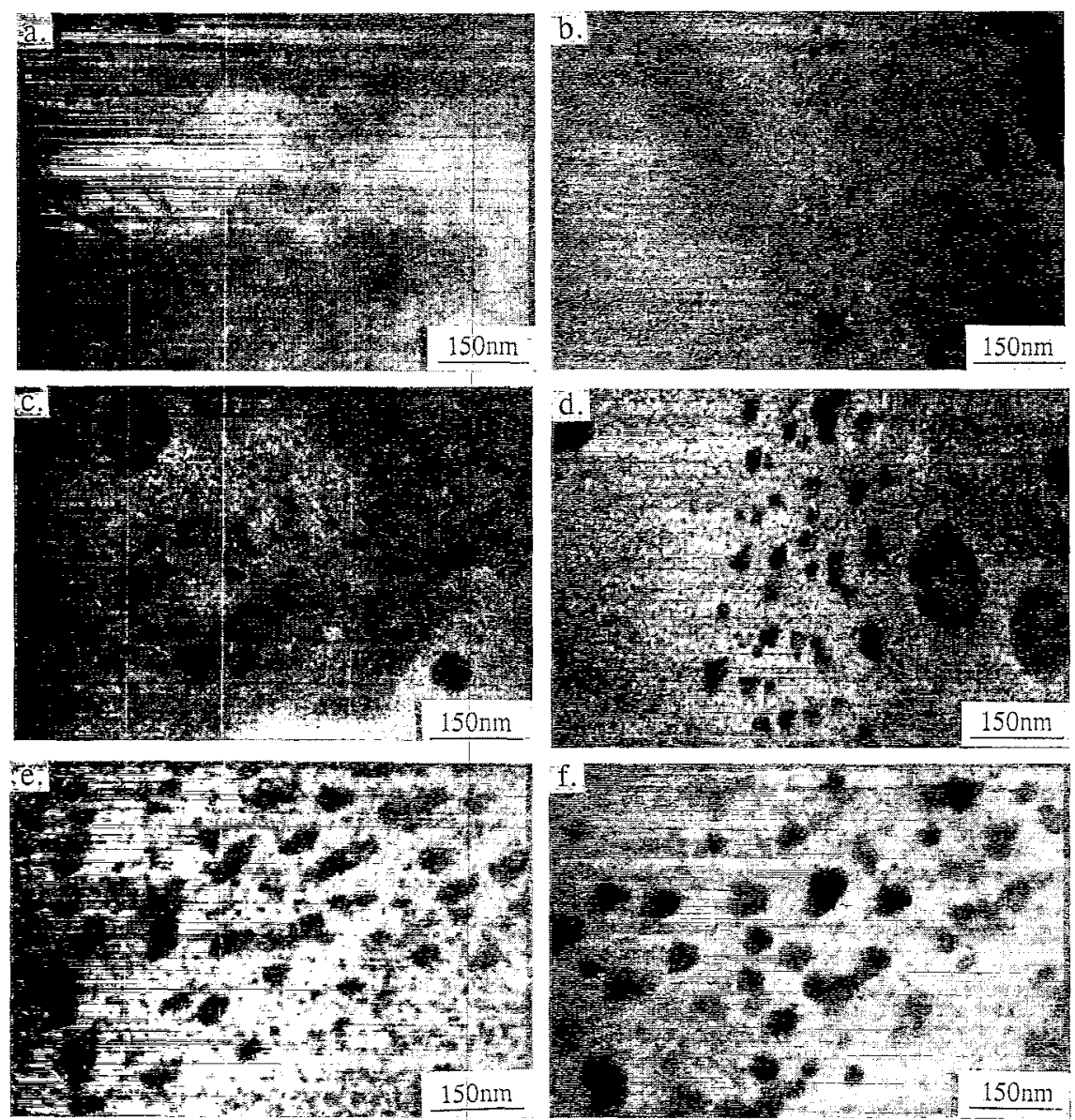

Fig. 4. TEM micrographs showing the grain boundary precipitates of the various tempers. (a) $7475 \mathrm{~S}-\mathrm{T} 4$; (b) $7475 \mathrm{~S}-\mathrm{T} 6$; (c) $7475 \mathrm{~L}-\mathrm{T} 6$; (d) 7475S-RRA; (e) 7475S-T73; (f) 7475L-T73.

cracking by means of mobile dislocations [7]. Therefore, it is reasonable to assume that the SCC resistance for the $7475 \mathrm{~S}$ alloy could be improved by increasing the degree of aging. On the other hand, an increasing size of GBPs has been proposed to explain the higher SCC resistance in the $7 \mathrm{xxx}$ series aluminum alloys [4]. The larger $\eta$ precipitates in the grain boundary can act as trapping sites for atomic hydrogen to nucleate hydrogen bubbles, thereby reducing hydrogen concentration below a critical value to retard hydrogen embrittlement and improve the SCC resistance [4,6,23]. Christodoulou and Flower [23] found that a critical precipitate size of approximately $20 \mathrm{~nm}$ for GBPs is required for nucleation of hydrogen bubble. The average size of GBPs in 7475S-T6 alloy is indicated in Table 7 to be smaller than $20 \mathrm{~nm}$, and conversely, the 7475L-T6 alloy possesses a larger average size of GBPs of approximately $25 \mathrm{~nm}$. Therefore, the 7475L-T6 alloy possesses a higher fraction of GBPs which are larger than a critical precipitate size required to form hydrogen bubbles than the 7475S-T6 alloy does. These results demonstrate that the SCC susceptibility of 7475S-T6 alloy would be larger than that of the 7475L-T6 alloy. Moreover, it seems that the PFZ width has no obvious effect on SCC susceptibility because the $7475 \mathrm{~S}-\mathrm{T} 6$ and the $7475 \mathrm{~L}-\mathrm{T} 6$ tempered alloys possess the similar width of PFZ, as shown in Table 7.

The size of GBPs in 7475S-T4 alloy should be smaller than a critical size necessary for nucleating hydrogen bubbles. The 7475S-T4 alloy exhibits long dislocation lines and planar slip bands, as shown in Fig. 5(a), which can transport atomic hydrogen over a longer distance and concentrate hydrogen at the intersection of dislocation and grain boundary [18]. It results in an easier to reach critical atomic hydrogen concentration which is necessary to embrittle grain boundaries [23]. Therefore, The wider slip band spacing and the smaller size of GBPs are considered to be the two most important factors leading to the serious SCC susceptibility of 7475S-T4 alloy.

The larger average GBPs size of about $33 \mathrm{~nm}$ in the 7475S-RRA treatment can effectively trap the atomic hydrogen in bubbles nucleated at GBPs inhibiting the hydrogen embrittlement. On the other hand, the 7475S- 

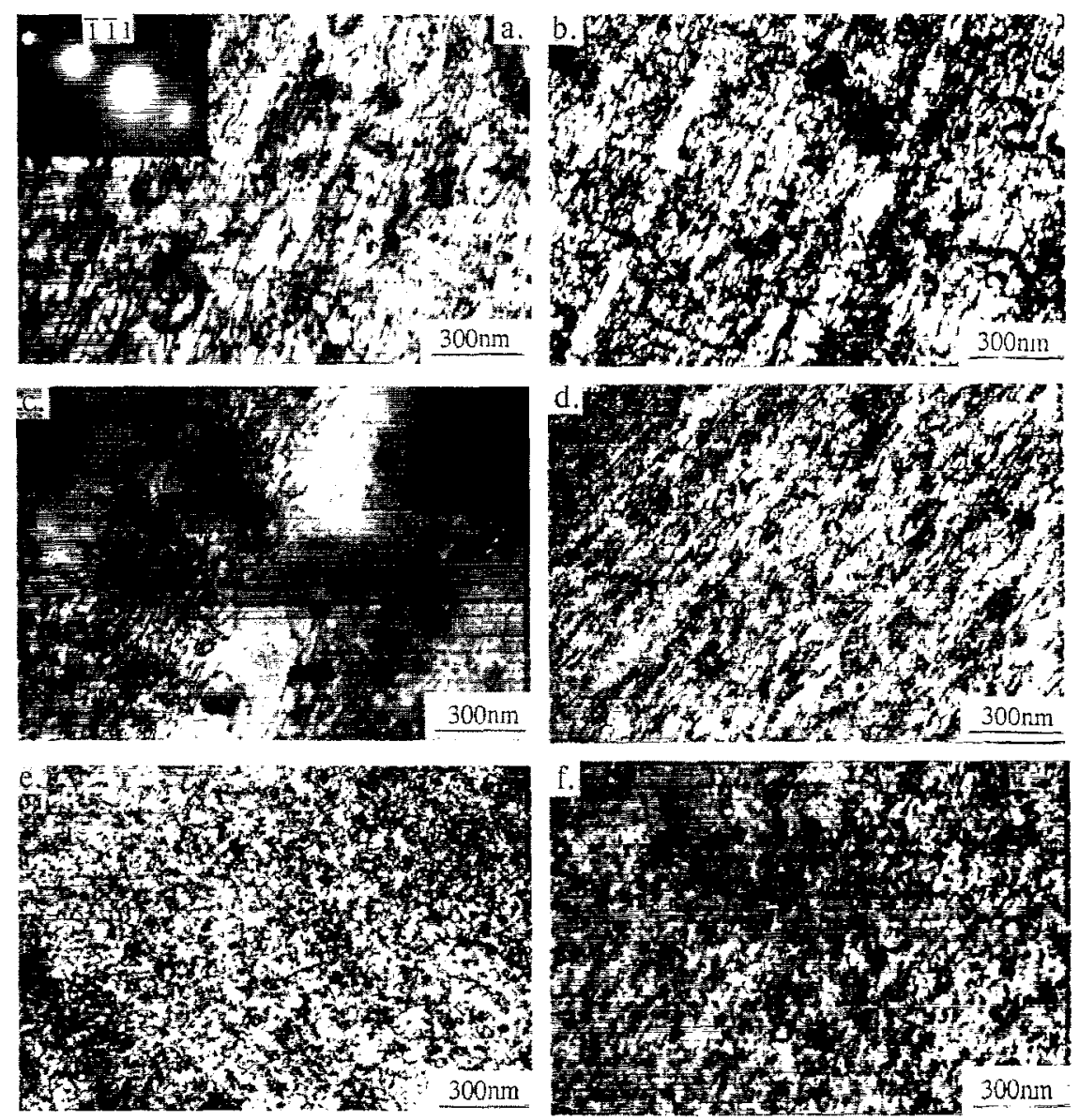

Fig. 5. TEM micrographs showing the deformation structure after $4 \%$ plastic strain for the various tempers. (a) 7475S-T4; (b) 7475S-T6; (c) 7475L-T6; (d) 7475S-RRA; (e) 7475S-T73; (f) 7475L-T73. [112] matrix zone axis and $g=\langle\overline{11}\rangle$ for all microgrtphs.

RRA alloy possesses more homogeneous slip type than the 7475S-T6 alloy, as indicated by a comparison of Fig. 5(b) with (d). It is due to a larger average matrix precipitate size and a higher fraction of $\eta^{\prime}$ (or $\eta$ ) matrix precipitates of the $7475 \mathrm{~S}-\mathrm{RRA}$. Therefore, the $7475 \mathrm{~S}$ RRA alloy could effectively improve the SCC resistance of 7475S-T6 alloy, which can be concluded that RRA temper can produce larger sizes of both the matrix precipitates and GBPs than T6 tempered condition.

Another significant effect produced by grain refinement is superplasticity [14,24]. A high strength aluminum alloy (like as 74755 alloy) presents fine grain size of about $10 \mu \mathrm{m}$, which is the fundamental condition for the superplasticity [24]. Staley [25] stated that the fine grain structure also contains a smaller size of GBPs. Therefore, the fine grain structure means that it easily results in undersized GBPs which are smaller than a critical precipitate size necessary for nucleating hydrogen bubbles. It reveals that a fine-grained aluminum alloy with unsuitable tempers or microstructural conditions would cause severe SCC damage, as ob- tained by the $7475 \mathrm{~S}-\mathrm{T} 4$ and $7475 \mathrm{~S}-\mathrm{T} 6$ alloys in this study. The elongation of the 7475S-T4 alloy, tested at a fast strain rate of $10^{-3} \mathrm{~s}^{-1}$ in air, is about of $20 \%$. The higher values of elongation for 7475S-T4 alloy, as demonstrated in Table 4 , are a result of grain refinement. However, the elongation of the 7475S-T4 alloy, tested at a slow strain rate of $4 \times 10^{-6} \mathrm{~s}^{-1}$ in air, is only about $8 \%$ as shown in Table 5. These results indicate that the 7475S-T4 alloy presents a severe atmospheric SCC susceptibility. The typical fracture surface of the SSRT specimen, tested in air, for the 7475S-T4 alloy appear as the obvious secondary cracks and intergranular fracture surfaces, as shown in Fig. 7(a) and (b). The above fractography conld not be found in any other tempered condition. A further conclusion can be inferred from the above result, if the size of GBPs is smaller than a critical precipitate size necessary for nucleating hydrogen bubbles, then the hydrogen embrittlement will become serious, and an improvement of the SCC resistance due to grain refinement can not be obtained. 

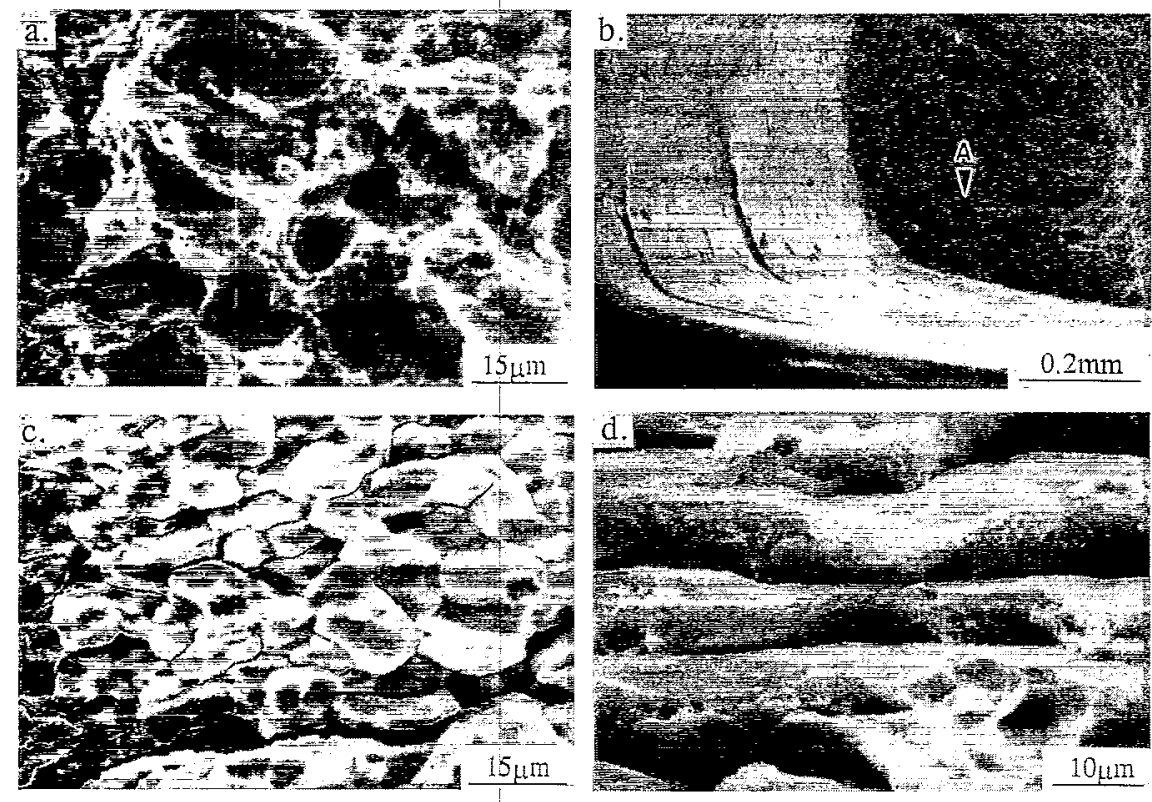

Fig. 6. Scanning electron fractographs of typical failed specimens. (a) Transgranular fracture of uncharged 7475S-T6 specimen; (b) and (c) are some isolated secondary cracks and equiaxed intergranular fracture surfaces of hydrogen-charged 7475S-T6 specimen, respectively; (d) pancakeshaped intergranular fracture surfaces of hydrogen-charged $7475 \mathrm{~L}-\mathrm{T} 6$ specimen.

\section{Conclusions}

(1) The same tendency between the hydrogen embrittlement susceptibility and the SCC susceptibility for all heat treatment conditions indicated that the mechanism of HIC plays a main role to control the SCC susceptibility of the 7475 aluminum alloys.

(2) A clear relationship has been found between the
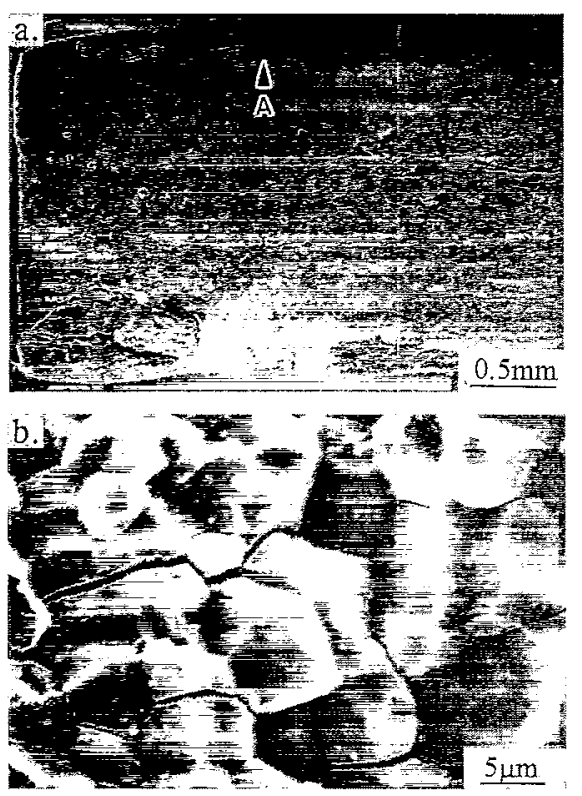

Fig. 7. Scanning electron fractographs of SSRT specimen for 7475ST4 alloy, tested in air. (a) Some intergranular fracture zones shown on fracture surfaces; (b) higher magnification of area $A$ in (a). grain refinement and the effect of microstructure on SCC susceptibility. Grain refinement presents a more homogeneous slip mode and a smaller size of GBPs. The more homogeneous slip mode is the major factor to reduce the SCC susceptibility. However, the SCC resistance can not be improved by means of grain refinement, if the GBPs size of the superplastic 7475 aluminum alloy is smaller than a critical precipitate size which is required for hydrogen bubble nucleation.

(3) GBPs size which is smaller than a critical precipitate size for nucleating hydrogen bubbles and a planar slip behavior cause the serious SCC susceptibility for the 7475S-T4 alloy. The RRA treatment could effectively improve the SCC resistance of T6 temper for superplastic 7475 aluminum alloy because RRA temper could produce larger sizes of both the matrix precipitates and GBPs than T6 tempered condition could.

(4) Fine grain size of the 7475 alloy does not only insure its superplastic characteristic, it also acts detrimentally as the main cause of inducing SCC. For preventing such a material failure from occurring, a suitable post heat treatment, such as RRA tempered treatment, should be employed to insure the application of this advanced superplastic alloy.

\section{Acknowledgements}

The authors are grateful to the support of National Science Council of the Republic of China under contract No. NSC 82-0405-E002-099. 


\section{References}

[1] M.O. Speidel, Metall, Trans., 6A (1975) 631.

[2] T.D. Burleigh, Corrosion, 47 (1991) 89.

[3] B.M. Cina, U.S. Patent 3856584, Dec. 24, 1974.

[4] J.K. Park and A.J. Ardell, Metall. Trans., 15A (1984) 1531.

[5] M.U. Islam and W. Wallace, Met. Technol., 10 (1983) 386.

[6] K. Rajan, W. Wallace and J.C. Beddoes, J. Mater. Sci, 17 (1982) 2817.

[7] J. Albrecht, I.M. Bernstein and A.W. Thompson, Metall. Trans., 13.A (1982) 811

[8] D.A. Hardwick, A.W. Thompson and I.M. Bernstein, Metall. Trans, $14 A$ (1983) 2517.

[9] R.J.H. Wanhill and G.F.J.A. van Gestel, Aluminium, 54 (1978) 573.

[10] J.A. Wert, N.E. Paton, C.H. Hamilton and M.W. Mahoney, Metall. Trans., 12A (1981) 1267.

[11] W. Gruhl, Ahminium, 54 (1978) 323.

[12] C.H. Hamilton and N.E. Paton (eds.), Superplasticity and Superplastic Forming, TMS, Warrendale, PA, USA, 1989.
[13] B. Baudelet, Mater. Sci. Eng., Al37 (1991) 41 .

[14] D.H. Shin, K.S. Kim, D.W. Kum and S.W. Nan, Metall. Trans., 21A (1990) 2729.

[15] T.C. Tsai and T.H. Chuang, Metall. Trans., 27A (1996) 2617.

[16] P.N. Adler, R. Deiasi and G. Geschwind, Metall. Trans, 3 (1972) 3191.

[17] P.K. Poulose, J.E. Morral and A.J. Mcevily, Metall. Trans., 5 (1974) 1393.

[18] D. Nguyen, A.W. Thompson and L.M. Bernstein, Acta Metall., 35 (1987) 2417

[19] R.N. Parkins, F. Mazza, J.J. Royuela and J.C. Scully, $B r$. Corros. J., 7 (1972) 154.

[20] G.M. Ludtka and D.E. Laughlin, Metall. Trans., 12A (1981) 2083.

[21] S. Ohsaki and T. Takahashi, J. Jpn Inst. Light Met., 35 (1985) 261.

[22] R. Braun, Mater. Sci. Eng., A190 (1995) 143.

[23] L. Christodoulou and H.M. Flower, Acta Metall., 28 (1980) 481.

[24] C.H. Hamilton and N.E. Paton (eds.), Superplasticity and Superplastic Forming, TMS, Warrendale, PA, USA, 1989.

[25] J.T. Staley, ASTM STP 605, 1976, p. 71. 